\title{
Pomza ve Diatomitin Portland Çimentosunun Basınç Dayanımına Etkilerinin ANFIS ile Tahmini Uğur GÜVENÇ ${ }^{1}$, Burak KOÇAK ${ }^{2, *}$
}

${ }^{1}$ Düzce Üniversitesi, Mühendislik Fakültesi, Elektrik Elektronik Mühendisliği Bölümü, 81600, Düzce, ORCID No: 0000-0002-5193-7990

${ }^{2}$ Düzce Üniversitesi, Fen Bilimleri Enstitüsü, Elektrik Elektronik Mühendisliği Anabilim Dalı, 81600, Düzce, ORCID No: 0000-0002-8640-1758

Anahtar Kelimeler:

ANFIS,

Çimento,

Pomza,

Diatomit,

Basınç dayanımı.
Özet: Bu çalışmada, çimento harçlarının basınç dayanımını tahmin etmek için uyarlamalı ağ tabanlı bulanık çıkarım sistemi (ANFIS) kullanılarak bir tahmin modeli geliştirilmiştir. $\mathrm{Bu}$ amaçla yapılan çalışmada, Portland çimentosu (PÇ) ile içerisine pomza (\%10-20), diatomit (\%10-20) ve pomza + diatomit $(\% 5+5-\% 10+10)$ ikame edilmiş olan toplam yedi farklı çimento ile elde edilen harçların 2, 7, 28, 90. hidratasyon günlerindeki basınç dayanımları standart çimento deneyleriyle belirlenmiştir. Deneyler sonucu elde edilen 168 veri eğitim için, bu deney sonuçlarının ortalamaları olan 28 veri de test için kullanılmıştır. ANFIS modelinde eğitim ve test aşamalarında hidratasyon günü, Portland çimento, pomza, diatomit ve su olarak 5 giriş parametresi ve çimento harçlarının basınç dayanımı olmak üzere 1 çıkış parametresi kullanılmıştır. Deneylerden elde edilen ve modelden elde edilen sonuçlarının kıyaslanmasında $\mathrm{R}^{2}$, MAPE ve RMSE olmak üzere üç farklı istatiksel yöntem kullanılmıştır. Elde edilen veriler, deney sonuçları ile ANFIS sonuçları arasında uyumun iyi olduğunu ve inşaat mühendisliğindeki uygulamalarda başarıyla uygulanabilirliğini göstermiştir.

\section{Prediction the Effects of Pumice and Diatomite on the Compressive Strength of Portland Cement with ANFIS}

Keywords:

ANFIS,

Cement,

Pumice,

Diatomite,

Compressive strength.

\begin{abstract}
In this study, a estimation model was developed using Adaptive-Network Based Fuzzy Inference Systems (ANFIS) to predict the compressive strength of cement mortars. In the study carried out for this purpose, a total of seven different cements in which Portland cement (PÇ) was substituted with pumice (10-20\%), diatomite (10-20\%) and pumice + diatomite $(5+5 \%-10+10 \%)$. The compressive strengths obtained from the mortars at the 2nd, 7th, 28th and 90th days of hydration were determined by standard cement tests. 168 data obtained as a result of the experiments were used for training, and 28 data, which are the averages of these experimental results, were used for testing. For the training and testing stages of the ANFIS model, 5 input parameters, namely hydration day, Portland cement, diatomite, pumice and water, and 1 output parameter, namely the compressive strength of cement mortars, were used. In the comparison of the experimental results and the results obtained from the model; three different statistical methods, namely $\mathrm{R}^{2}$, MAPE and RMSE, were used. The obtained data showed that there is a good agreement between the test results and the ANFIS results and that it can be successfully applied in civil engineering applications.
\end{abstract}

\section{GİRIŞ}

Günümüzde birçok alanda olduğu gibi inşaat mühendisliği uygulamalarında çeşitli problemleri çözmek için, bulanık mantık, yapay sinir ağları, makine öğrenmesi gibi yapay zeka tabanlı uygulamalar yaygın ve etkin olarak kullanılmaktadır [1-11]. Uyarlamalı ağ tabanlı bulanık çıkarım sistemi (ANFIS) de bu uygulamalardan biri olarak oldukça güvenilir bir yöntem olarak ifade edilmekte ve bir çok araştırmacı tarafindan oldukça yaygın olarak kullanılmaktadır.

Bu çalışmalardan birinde Sakthivel vd. (2016), hibrit örgü ve elyaf takviyeli çimento esaslı kompozit döşeme elemanlarının eğilme mukavemetlerinin yapay sinir ağı kullanarak modellenmesi ve tahmini için yapmış oldukları 
çalışmada, üç model geliştirilmiş ve çeşitli denemelere dayalı olarak gizli katmanlar için nöron sayısı belirlenmiştir. Elde etmiş oldukları sonuçlara göre her üç modelin de en yüksek korelasyon katsayısına $\left(\mathrm{R}^{2}\right)$ dayalı olarak \%93,3, \%99,8 ve \%98,8 değerleri ile başarılı modeler olduğunu ve böylece YSA'nın, önceki deneysel çalışmalardan veya ampirik veya teorik verilerden elde edilen değerleri tahmin etmede etkili bir teknik olabileceğini ve yeni deneylerin yürütülmesinde zaman ve maliyet tasarrufu sağlayabileceği sonucuna ulaşmışlardır [12].

Diğer bir çalışmada Mansouri ve Kisi (2015), güçlendirilmiş duvar elemanlarının bağlanma mukavemetini tahmin etmek için ANFIS ve YSA modelleri geliştirmiş ve bu modelleri çoklu doğrusal olmayan regresyon, çoklu doğrusal regresyon ve mevcut bağ gücü modelleri ile karşılaştırmışlardır. Elde edilen sonuçlara göre YSA ve ANFIS modellerinin diğer modellere göre daha iyi performans gösterdiğini ve sonradan donatılan kagir elemanların bağlanma mukavemetinin tahmininde başarılı bir şekilde kullanılabileceğini ifade etmişlerdir [13].

Bir başka çalışmada Koçak ve Gülbandılar (2016), zeolit ve diatomit ikameli betonların $\mathrm{MgSO}_{4}$ etkisindeki davranışlarını ANFIS tahmin modeli ile 7 farklı karışımdan elde edilen 63 örneğin 28., 56. ve 90. hidratasyon günlerindeki basınç dayanımlarını tahmin etmeye çalışmışlardır. Sonuç olarak deneysel sonuçlar ile tahmin edilen basınç dayanım sonuçlarını kıyaslamışlar ve neredeyse deney sonuçları ile aynı sonuçları tahmin ederek bu modelin faydalı ve güçlü bir model olduğunu belirtmişlerdir [14].

Armaghani ve Asteris (2021) bir başka çalışmada metakaolin katkılı çimento esaslı harç malzemelerinin basınç dayanımının tahmini için literatürde mevcut deneysel veriler kullanılarak YSA ve ANFIS modelleri oluşturmuş ve bu yöntemleri karşılaştırmışlardır. Bu amaçla modelleri oluşturmak için hidratasyon yaşı (gün), maksimum agrega çapı $(\mathrm{mm})$, metakaolin/bağlayıcı oranı $(\%), \quad$ su/bağlayıcı oranı, super akışkanlaştırıcı, bağlayıcı/kum oranı olarak altı giriş, basınç dayanımı olarak bir çıkış parametresini kullanmışlardır. Daha sonra performans indeksleri olarak $\mathrm{R}^{2}$, VAF, RMSE, MAE ve a10 indeksi kullanılarak en iyi YSA modeli ve en iyi ANFIS modelini karşılaştırmışlardır. Tüm performans indeksleri açısından, geliştirilen hem YSA hem de ANFIS modelinin iyi sonuç verdiği ancak önerilen modelin YSA modeli olduğu belirtilmiştir [15].

Amin vd. (2021) bir diğer çalışmada doğal volkanik kül harcının (VAM) basınç dayanımını modellemek için bir YSA ve ANFIS modeli kullanmışlardır. Çalışmada öngörülen modelleri eğitmek ve test etmek için literatürden 150 'den fazla veri toplanmıştır. Bunun yanı sıra laboratuvarda değişen oranlarda volkanik kül içeren harç numuneleri hazırlayarak test etmişler ve sonuçları modellerin doğrulanması için kullanmışlardır. Geliştirilen modellerin performansı çok sayıda istatistiksel ölçüm kullanılarak değerlendirilmiş, elde edilen verilere göre hem YSA hem de ANFIS modellerinin, $\mathrm{R}^{2}$ değerlerinin 0.9'un üzerinde ve daha düşük hata istatistikleriyle basınç dayanımını doğru bir şekilde tahmin ettiğini ifade etmişlerdir [16].

$\mathrm{Bu}$ çalışmalar ışığında yapılan bu çalışmayla Portland çimentosunun basınç dayanımına pomza ve diatomitin etkisi, bir ANFIS modeli geliştirilerek tahmin edilmeye çalışılmıştır. $\mathrm{Bu}$ amaçla Portland çimentosu (PÇ) ile içerisine pomza (\%10-20), diatomit (\%10-20) ve pomza+diatomit $(\% 5+5-\% 10+10)$ ikame edilmiş olan 7 farklı çimento hazırlanmış, bu çimentolarla da 7 grup çimento harc1 üretilmiş, her tip çimento harc1 için de 6 örnek hazırlanmıştır. Daha sonra bu örnekler, 2, 7, 28 ve 90. hidratasyon günlerinde basınç dayanımına tabi tutulmuşlardır. ANFIS tahmin modelinin eğitim ve test aşamaları hidratasyon günü, Portland çimento, pomza, diatomit ve su olmak üzere 5 giriş parametresi ve çimento harçlarının basınç dayanımı olmak üzere 1 çıkış parametresinden oluşmaktadır. Modelin eğitimi için çimento harç basınç dayanımı deneylerinden elde edilen 168 veri, test edilmesi için de her bir deney için standartlarda belirtilen esaslar çerçevesinde alınması gereken bu deney sonuçlarının ortalamaları olan 28 adet veri kullanılmıştır. Daha sonra çimento harçlarının basınç dayanımları ile modelden elde edilen veriler kıyaslanmış ve çalışmanın ilgili bölümlerde ayrıntısı ile verilmiştir.

\section{DENEYSEL TASARIM}

\subsection{Malzemeler}

Çimento harçlarının hazırlanmasında malzeme olarak Portland çimentosu, diatomit, pomza, standart kum ve su kullanılmıştır. Kullanılan çimento, Eskişehir ÇİMSA çimento tesislerinde TS EN 197-1 standardına göre üretilmiş CEM I 42,5 R tipi Portland çimentosudur [17]. Pomza Ispartada bulunan Betaş AŞ'den, Diatomit ise EP Mineral adlı bir ticari firmadan temin edilmiştir. Harç numunelerinin üretilmesinde standart kum ve Eskişehir iline ait şebeke suyu kullanılmıştır. PÇ, pomza ve diatomitin kimyasal ve fiziksel özellikleri sırasıyla Tablo 1 ve 2 'de verilmiştir.

Tablo 1. Malzemelerin kimyasal özellikleri

\begin{tabular}{|l|c|c|c|}
\hline $\begin{array}{c}\text { Kimyasal } \\
\text { ozzellikler }\end{array}$ & $\begin{array}{c}\text { Çimento, } \\
\%\end{array}$ & $\begin{array}{c}\text { Pomza, } \\
\%\end{array}$ & $\begin{array}{c}\text { Diatomit, } \\
\%\end{array}$ \\
\hline $\mathrm{SiO}_{2}$ & 20,36 & 56,32 & 85,69 \\
\hline $\mathrm{Al}_{2} \mathrm{O}_{3}$ & 4,6 & 16,51 & 2,1 \\
\hline $\mathrm{Fe}_{2} \mathrm{O}_{3}$ & 2,56 & 3,93 & 0,96 \\
\hline $\mathrm{CaO}$ & 62,57 & 4,84 & 0,54 \\
\hline $\mathrm{MgO}$ & 1,53 & 1,87 & 0,32 \\
\hline $\mathrm{SO}_{3}$ & 3,32 & 0,23 & 0,03 \\
\hline $\mathrm{Na}_{2} \mathrm{O}$ & 0,26 & 5,18 & 0,25 \\
\hline $\mathrm{K}_{2} \mathrm{O}$ & 0,66 & 5,09 & 0,18 \\
\hline $\mathrm{Cl}^{-}$ & 0,018 & 0,01 & 0,013 \\
\hline $\begin{array}{l}\mathrm{K} 1 z d 1 r m a \\
\text { kayb1 }\end{array}$ & 2,38 & 2,65 & 9,97 \\
\hline Serbest $\mathrm{CaO}$ & 1,78 & - & - \\
\hline
\end{tabular}


Tablo 2. Malzemelerin fiziksel özellikleri

\begin{tabular}{|c|c|c|c|c|}
\hline \multirow[b]{2}{*}{ Malzemeler } & \multirow{2}{*}{$\begin{array}{l}\text { Blaine } \\
\text { (Özgül } \\
\text { yüzey), } \\
\mathrm{cm}^{2} / \mathrm{g}\end{array}$} & \multirow{2}{*}{$\begin{array}{l}\text { Özgül } \\
\text { ağırlık, } \\
\mathrm{g} / \mathrm{cm}^{3}\end{array}$} & \multicolumn{2}{|c|}{$\begin{array}{c}\text { Tane boyutu } \\
\text { (elek üstü), } \\
\%\end{array}$} \\
\hline & & & $\begin{array}{l}>90 \\
\mu \mathrm{m}\end{array}$ & $\begin{array}{l}>45 \\
\mu \mathrm{m}\end{array}$ \\
\hline Çimento & 3822 & 3,18 & 3,2 & 0,0 \\
\hline Pomza & 2645 & 2,70 & 7,8 & 40,5 \\
\hline Diatomit & 6112 & 2,58 & 0,1 & 0,0 \\
\hline
\end{tabular}

\section{2. Çimento Harçlarının Hazırlanması}

Deney numunelerinin hazırlanması için Portland çimentosu (PÇ) ile içerisine pomza (\%10-20), diatomit (\%10-20) ve pomza+diatomit $(\% 5+5-\% 10+10)$ ikame edilmiş olan toplam yedi çimento üretilmiştir. $\mathrm{Bu}$ çimentoların kodları Tablo 3 'te verilmiştir.

Tablo 3. Çimento kodları

\begin{tabular}{|c|l|c|}
\hline Çimento & Çimento tipi & Kodu \\
\hline 1 & PÇ & R \\
\hline 2 & Diatomit ikameli çimento, \%10 & 10D \\
\hline 3 & Diatomit ikameli çimento, \%20 & 20D \\
\hline 4 & Pomza ikameli çimento, \%10 & 10P \\
\hline 5 & Pomza ikameli çimento, \%20 & 20P \\
\hline 6 & $\begin{array}{l}\text { Pomza ve Diatomit ikameli } \\
\text { çimento, \%5+5 }\end{array}$ & 5P5D \\
\hline 7 & $\begin{array}{l}\text { Pomza ve Diatomit ikameli } \\
\text { çimento, \%10+10 }\end{array}$ & 10P10D \\
\hline
\end{tabular}

Basınç dayanımlarının belirlenmesi için $450 \mathrm{~g}$ çimento, 1350 g kum ve 225 g su kullanılarak TS EN 196-1'deki esaslara göre üretilen çimento harçları $4 \times 4 \times 16 \mathrm{~cm}$ boyutlarında üç gözlü kalıplara döküldükten sonra her kalıp sarsma cihazına yerleştirilerek standartta belirtilen esaslara göre sarsılmıştır. Daha sonra harç örnekleri 24 saat laboratuvarda bekletilmesinin ardından kalıplardan çıkarılarak $20 \quad{ }^{\circ} \mathrm{C}$ sıcaklıktaki kür havuzlarına yerleştirilmiştir. Numuneler 2, 7, 28 ve 90. hidratasyon günlerinde havuzlardan alınıp kurulanarak uygun bir şekilde ortalarından kırılmış ve yarım prizma şeklindeki bu numunelerin TS EN 196-1 standardındaki esaslar çerçevesinde basınç dayanımları elde edilmiştir [18].

\section{ADAPTİ AĞ YAPISINA DAYALI BULANIK ÇIKARIM SISTEMI}

Adaptif ă̆ yapısına dayalı bulanık çıkarım sistemi (ANFIS), sinir ağlarını ve bulanık çıkarım sistemlerini içeren karma bir sistem olarak tanımlanmaktadır. Sinirsel ağ uyarlanabilirliği irdelerken, bulanık çıkarım ise belirsizlik ve karasızlık durumlarını irdelemektedir. Karma sistemler genellikle Sugeno bulanık model olarak adlandirılmaktadır.

Bulanık kural formatı tipik olarak aşağıda olduğu gibi gösterilmektedir.

if $x$ is $A$ and $y$ is $B$ then $z=f(x, y)$

Burada yer alan $\mathrm{z}=\mathrm{f}(\mathrm{x}, \mathrm{y})$ çıkarımdaki ham fonksiyonu, A ve $B$ ise bulanık önerme kümelerini belirtmektedir. Genellikle $f(x, y)$, $x$ ve y giriş değişkenlerini ifade eden polinom fonksiyonudur. Eğer $\mathrm{f}(\mathrm{x}, \mathrm{y})$ birinci dereceden ise, bu modele birinci derece Sugeno bulanık model tanımlaması yapılmaktadır. Burada f sabit ise bu durumda da sifirınc1 derece Sugeno bulanık model tanımlaması yapılmaktadır. Birinci dereceden Sugeno bulanık çıkarım sisteminde iki bulanık çıkarım if-then kuralları Denklem 1 ve 2'de örneklendirilmiştir.

Kural 1: if $x$ is $A_{1}$ and $y$ is $B_{1}$, then $f_{1}=p_{1} x+q_{1} y+r_{1}$

Kural 2: if $x$ is $A_{2}$ and $y$ is $B_{2}$, then $f_{2}=p_{2} x+q_{2} y+r_{2}$

$\mathrm{Bu}$ çıkarım sistemindeki her bir kuralın çıkışı, sabit terimin eklenmesi ile giriş değişkenlerinin doğrusal bir kombinasyonu, son çıkış ise her bir kuralın çıkışının ağırlık ortalaması olarak ifade edilmektedir $\left(\bar{w}_{i}\right)[5,19$ 21].

Bir ANFIS mimarisinin temel yapısı Şekil 1'deki gibi örneklenebilir.

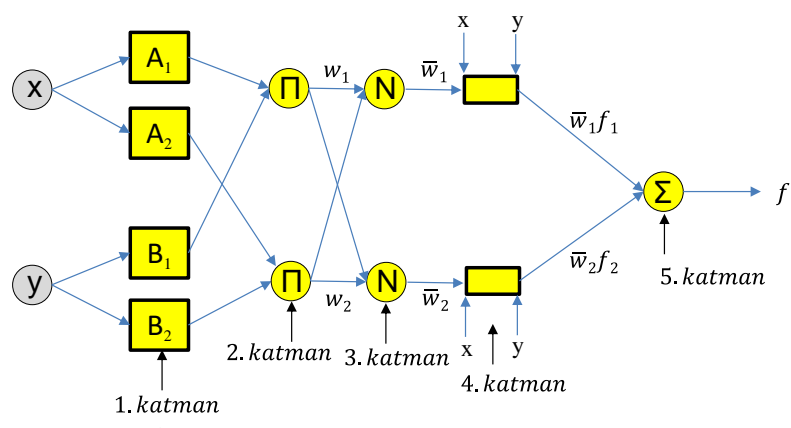

Şekil 1. İki girişli ve iki kurallı ANFIS mimarisi [20]

Aşağıda bu katmandaki düğüm fonksiyonunun davranışları ayrıntılı olarak ifade edilmektedir.

1. Katman: Birinci katmandaki her $i$ düğüm, düğüm fonksiyonuyla uyumlu davranış göstermekte ve çıkışı aşağıdaki gibi ifade edilmektedir.

$\begin{array}{ll}o_{l, 1}=\mu A_{(i)}(x), & i \text { çin } i=1,2, \text { veya } \\ o_{l, 1}=\mu B_{(i-2)}(y), & i \text { çin } i=3,4\end{array}$

Burada $x$ veya $y$, i-inci düğüm için girişleri, $A_{i}$ veya $B_{i-2}$ $k \imath s a$, uzun gibi dilsel ifadeleri, yani $o_{l, 1}$, A veya B bulanık kümelerinin üyelik derecelerini belirtmekte olup Denklem 3'teki gibi gösterilmektedir.

$o_{l, 1}=\mu A_{i}(x)=\frac{1}{1+\left[\left(x-c_{i}\right) / a_{i}\right]^{2 b_{i}}}$

Burada $\mathrm{a}_{i}, \mathrm{~b}_{i}, \mathrm{c}_{i}$ küme parametrelerini belirtmektedir. $\mathrm{Bu}$ parametrelerin değerleri genelleştirilmiş çan eğrisi üyelik fonksiyonu için $A_{i}$ dilsel etiketin üyelik derecesini belirtmektedir. Üyelik fonksiyonu tipine göre bu üyelik derecesi fonksiyonları değişik tiplerde bulunmakta ve Denklem 3'teki gibi değişiklik göstermektedir. Bu katmandaki parametreler öncül parametreler olarak tanımlanmakta olup bu katmanın çıkışı, öncül kısmın üyelik derecesinin değeri olarak ifade edilmektedir.

2. Katman: İkici katmandaki her bir düğüm, bir kuralın bulanık çıkarımı ve cebirsel çarpma operatörü yardımıyla Denklem 4'teki gibi hesaplanmaktadır. 
$o_{l, 2}=w_{i}=\mu A_{i}(x) \cdot \mu B_{i}(y)$ için $i=1,2, \ldots, n$

3. Katman: Üçüncü katmandaki $i$-inci düğüm, bulanık çıkarımların, bütün düğümlerin bulanık çıkarımlarının toplamina oranlanmasiyla Denklem 5'teki gibi hesaplanmaktadır.

$o_{l, 3}=\overline{w_{l}}=\frac{w_{i}}{w_{1}+w_{2}+\cdots+w_{n}} \quad$ için $i=1,2, \ldots, n$

$\mathrm{Bu}$ katmanın çıkışları normalize edilmiş olarak adlandirılir.

4. Katman: Dördüncü katmandaki $i$-inci düğüm, düğüm fonksiyonu ve normalize çıkışın çarpılmasıyla Denklem 6'daki gibi hesaplanmaktadir.

$o_{l, 4}=\overline{w_{l}} \cdot f_{i}=\overline{w_{l}} \cdot\left(p_{i} \cdot x+q_{i} \cdot x+r_{i}\right) i c ̧ i n i 1,2, \ldots, n$

$\mathrm{Bu}$ katmandaki parametreler, ardıl parametreler olarak tanımlanmakta olup $\bar{w}_{i}, 3$-üncü katmanın $i$-inci düğümün çıkışını, $p_{i}, q_{i}, r_{i}$ parametre kümesini belirtmektedir.

5. Katman: Beşinci katmanın tek sabit düğümündeki $\Sigma$ etiketi, son çıkış olarak bütün gelen işaretlerin toplamı olarak Denklem 7'deki gibi hesaplanmaktadır.

$o_{l, 5}=\sum_{i} \overline{w_{l}} . f_{i}=\frac{\sum_{i} w_{i} \cdot f_{i}}{\sum_{i} w_{i}}$ için $i=1,2, \ldots, n$

ANFIS modelinin genel işlev düzeninin açıklandığı bu yapı sabit değildir ve istenildiği gibi değiştirilebilmektedir $[5,19-22]$.

\section{ANFIS MODEL PARAMETRELERİ}

ANFIS model eğitimi için hazırlanan çimento harç numunelerinin basınç dayanımı deneylerinden elde edilen 168 veri eğitim için, her bir deney için standartlarda belirtilen esaslar çerçevesinde alınması gereken bu deney sonuçlarının ortalamaları olan 28 adet veri ise test için kullanılmıştır. ANFIS modelinin eğitim ve test aşamaları, hidratasyon günü, Portland çimento, pomza, diatomit ve su olmak üzere 5 giriş parametresi ve çimento harçlarının basınç dayanımı olmak üzere 1 çıkış parametresinden oluşmaktadır. ANFIS modeline ait giriş ve çıkış parametrelerinin minimum ve maksimum değerleri Tablo 4'te verilmiştir.

Tablo 4. ANFIS Modelinin giriş ve çıkış parametreleri

\begin{tabular}{|l|l|c|c|}
\hline \multicolumn{2}{|c|}{} & \multicolumn{2}{|c|}{$\begin{array}{c}\text { Ĕ̈itim ve test } \\
\text { verileri }\end{array}$} \\
\cline { 3 - 4 } \multicolumn{2}{|c|}{} & Min. & Max. \\
\hline \multirow{4}{*}{$\begin{array}{l}\text { Giriş } \\
\text { parametreleri }\end{array}$} & Gün & 2 & 90 \\
\cline { 2 - 4 } & PÇ, g & 360 & 450 \\
\cline { 2 - 4 } & Diatomit, g & 0 & 90 \\
\cline { 2 - 4 } & Pomza, g & 0 & 90 \\
\cline { 2 - 4 } & Su, g & 225 & 270 \\
\hline $\begin{array}{l}\text { Çı1k1ş } \\
\text { parametreleri }\end{array}$ & $\begin{array}{l}\text { Basınç } \\
\text { dayanımı, MPa }\end{array}$ & 17,4 & 62,7 \\
\hline
\end{tabular}

ANFIS modellerinin geliştirilmesi için MATLAB programındaki bulanık mantık araç kutusunda bulunan
ANFIS editöründen faydalanılmıştır. Bulanıklaştırma aşamasında kullanılacak üyelik fonksiyonlarının şekli, yatay eksendeki konumuna ve alt küme sayısına bağlı olarak belirlenmektedir. Modellemede üyelik fonksiyonlarındaki bu özelliklerin belirlenebilmesi, modelin başarısı açısından çok önemlidir. Bu özelliklerin en iyi şekilde belirlenebilmesi için bulanıklaştırma işleminden önce kaynak araştırması yapılarak çalışmamıza benzer konularda yapılan çalışmalar incelenmiştir. Yapılan araştırma sonucunda bu çalışma için Gauss2 üyelik fonksiyonu seçilmiş, farklı epochlarla farklı öğrenme algoritmaları denenmiştir. Seçilen ANFIS modellerinin genel yapısı Şekil 2'de, toplam parametre değerleri Tablo 5'te verilmiştir.

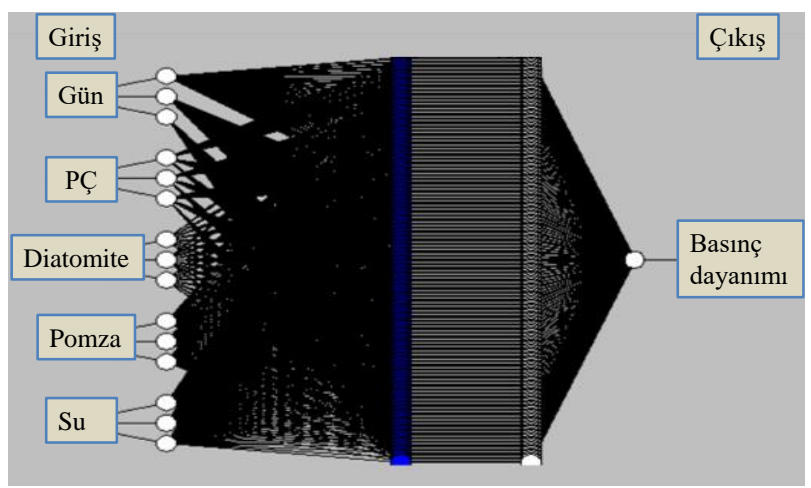

Şekil 2. ANFIS modelin blok şeması

Tablo 5. ANFIS Modelinin parametre değerleri

\begin{tabular}{|l|c|}
\hline Parametre bilgisi & ANFIS \\
\hline Giriş says1 & 5 \\
\hline Çı1ş sayıs1 & 1 \\
\hline Düğum sayıs1 & 524 \\
\hline Doğrusal parametre sayıs1 & 243 \\
\hline Doğrusal olmayan parametre sayıs1 & 60 \\
\hline Toplam parametre sayıs1 & 303 \\
\hline Eğitim veri çifti sayı11 & 168 \\
\hline Toplam bulanık kural sayı11 & 243 \\
\hline İterasyon (Epoch sayıs1) & 2 \\
\hline
\end{tabular}

Çalışmada tercih edilen modelden elde edilen giriş değişkenlerinin üyelik fonksiyonları Şekil 3'te verilmiştir.

\section{BULGULAR}

ANFIS modelinde kullanılan deneylerden elde edilip eğitiminde kullanılan 168 ve test için kullanılan numunelere ait 28 basınç dayanımı değeri sırasıyla Şekil 4 ve Şekil 5 'te verilmiştir.

ANFIS modelinde eğitim için kullanılan numunelerin basınç dayanımları 2 günlük numune için 17,4 ile 31,6 $\mathrm{MPa}$ arasında, 7 günlük numune için 28,2 ile 44,3 $\mathrm{MPa}$ arasında, 28 günlük numune için 44,6 ile $55 \mathrm{MPa}$ arasında, 90 günlük numune için 49,9 ile $62,7 \mathrm{MPa}$ arasında farklı değerler almıştır. 

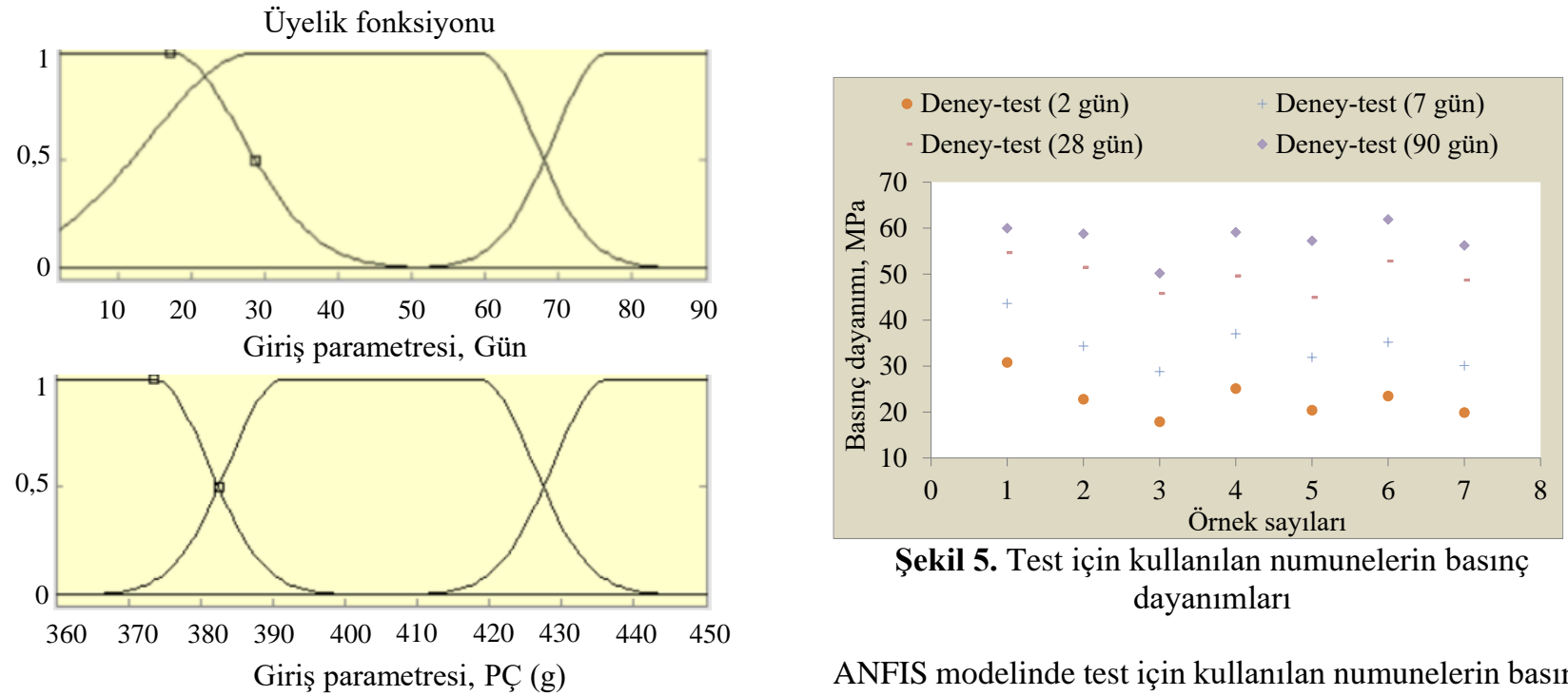

Şekil 5. Test için kullanılan numunelerin basınç dayanımları

ANFIS modelinde test için kullanılan numunelerin basınç dayanımları 2 günlük numune için 17,9 ile 30,8 $\mathrm{MPa}$ arasında, 7 günlük numune için 28,8 ile $43,6 \mathrm{MPa}$ arasında, 28 günlük numune için 44,9 ile $54,7 \mathrm{MPa}$ arasında, 90 günlük numune için 50,2 ile $61,9 \mathrm{MPa}$ arasında farklı değerler almıştır.

Test aşamasındaki ANFIS modelinden elde edilen tahmin değerleri ile deney sonuçlarından elde edilen veriler Şekil 6'da verilmiştir.
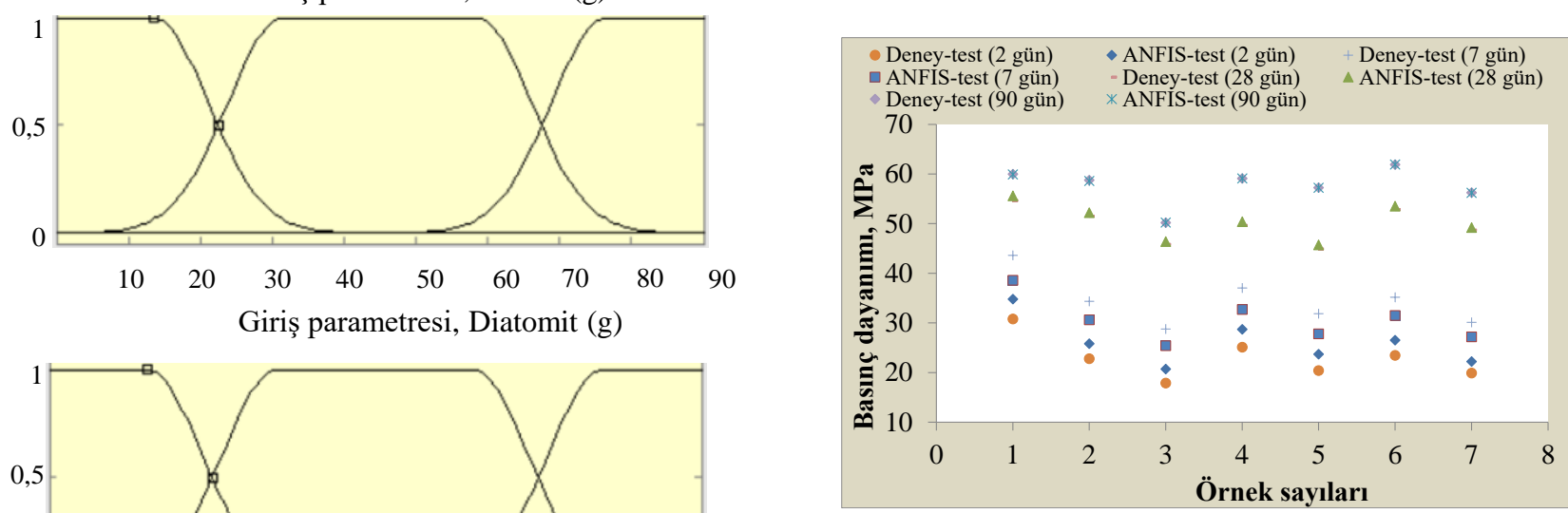

Şekil 6. Test aşamasındaki deney ve modelden elde edilen basınç dayanımları

Deneysel sonuçlar ile modelden elde edilen sonuçlari; regresyon analiz $\left(\mathrm{R}^{2}\right)$, ortalama mutlak yüzde hata (Mean Absolute Percentage Error-MAPE) ve hata kareleri ortalamasının karekökü (Root Mean Square Error-RMSE) olmak üzere üç farklı istatiksel yöntem ile karşılaştırılmıştır. Bu yöntemlerin formülleri Denklem (8), (9) ve (10)'da verilmiştir.

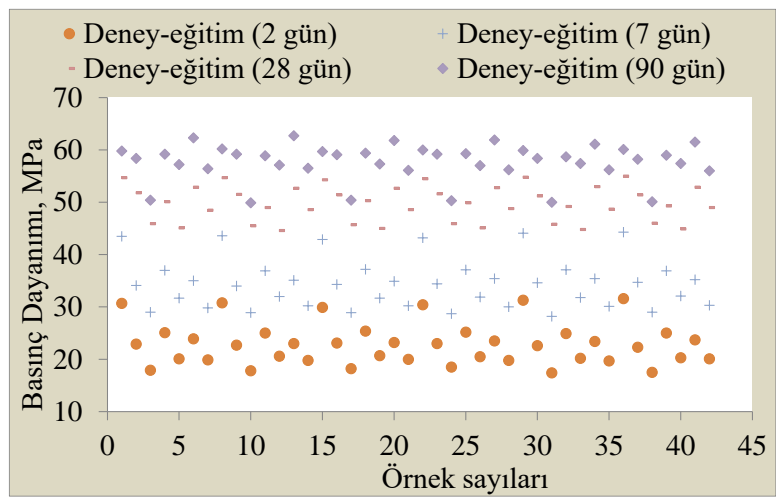

$R M S E=\sqrt{\frac{1}{N}} \sum_{i=1}^{N}\left(y_{i}-r_{i}\right)^{2}$

$M A P E=\frac{100}{n} \sum_{i=1}^{N}\left|\frac{r_{i}-y_{i}}{r_{i}}\right|$

$R^{2}=1-\frac{\sum_{i=1}^{N}\left(y_{i}-r_{i}\right)^{2}}{\sum_{i=1}^{N}\left(r_{i}-y_{m}\right)^{2}}$

Burada N kullanılan veri kümesi sayısını, $\mathrm{y}_{\mathrm{i}}$ tahmin edilen değeri, $r_{i}$ gerçek değeri $y_{m}$ ise gerçek değerlerin ortalamasını ifade etmektedir $[12,19]$. 
ANFIS modelinden elde edilen tahmin değerleri ve 2, 7, 28 ve 90 . hidratasyon günlerindeki basınç dayanımları ile hesaplanan $\mathrm{R}^{2}$, RMS ve MAPE gibi istatistiksel veriler Şekil 7'de verilmiştir.

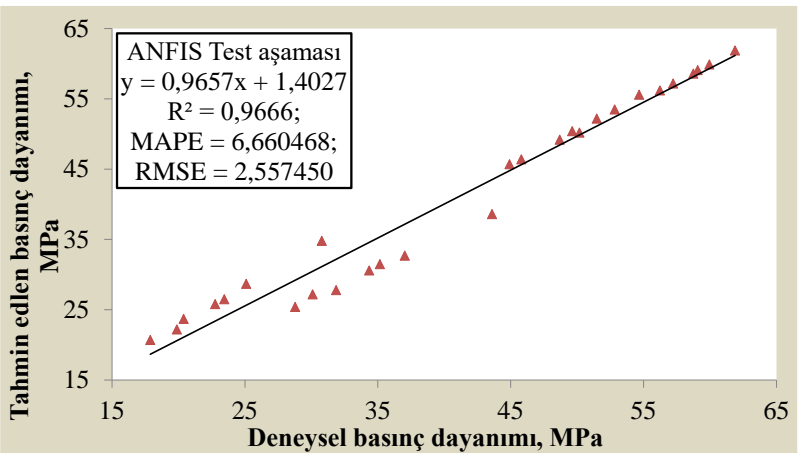

Şekil 7. Test aşamasındaki deney ve modelden elde edilen verilerin istatistiksel özellikleri

Elde edilen test aşamasındaki sonuçlara göre ANFIS modelinin $\mathrm{R}^{2}$ değerinin 0,9666, MAPE değerinin 6,660468 ve RMSE değerinin ise 2,557450 olarak

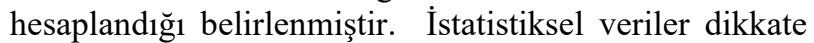
alındığında tüm ANFIS modelleri için $\mathrm{R}^{2}$ değerlerinin \%96'nın üzerinde elde edildiği, dolayısı ile iyi bir topolojiye sahip olduğu ifade edilebilir.

Bunun yanı sıra test aşamasındaki gerçek değerlerle modelden elde edilen basınç dayanımlarının kıyaslanması için 2, 7, 28 ve 90. hidratasyon günündeki veriler sırasıyla Şekil $8,9,10$ ve 11 'de verilmiştir.

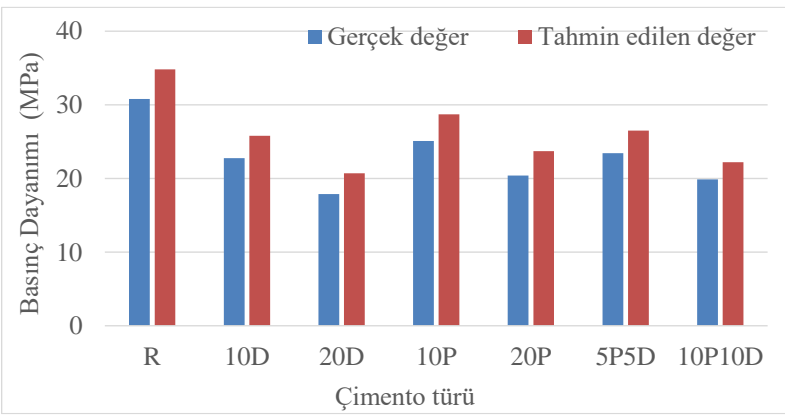

Şekil 8. 2. Hidratasyon günündeki gerçek değerler ile modelden elde edilen basınç dayanımları

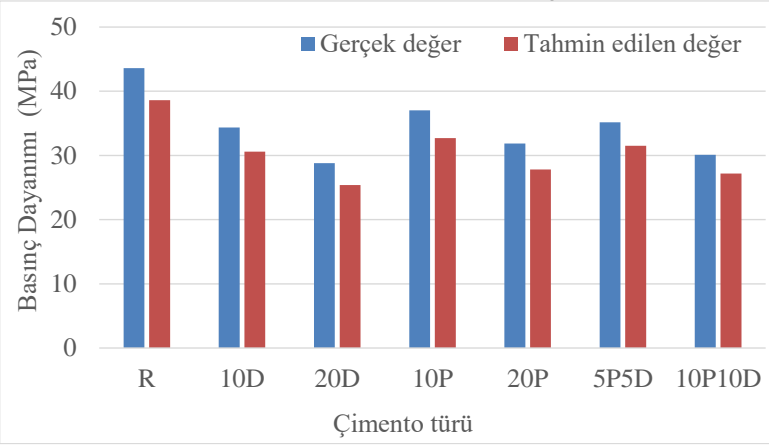

Şekil 9. 7. Hidratasyon günündeki gerçek değerler ile modelden elde edilen basınç dayanımları

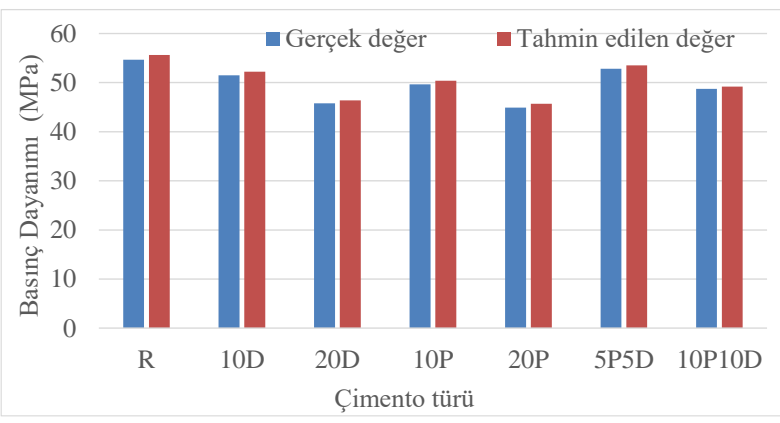

Şekil 10. 28. Hidratasyon günündeki gerçek değerler ile modelden elde edilen basınç dayanımları

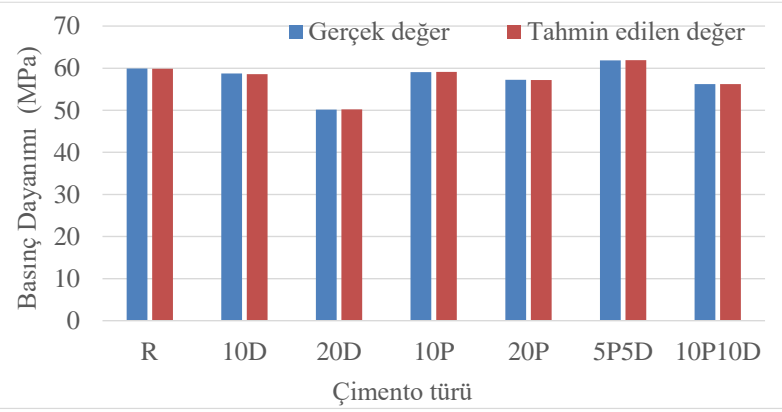

Şekil 11. 90. Hidratasyon günündeki gerçek değerler ile modelden elde edilen basınç dayanımları

2. hidratasyon günündeki basınç dayanımları dikkate alındığında en fazla değişimin -3,30 MPa farkla \%16,18 hata oranıla (Şekil 1), 7. hidratasyon gününde en fazla değişimin 4,07 MPa farkla \%12,76 hata oranıyla (Şekil 2), 28. idratasyon gününde en fazla değişimin $-0,78 \mathrm{MPa}$ farkla \%1,74 hata oranıyla (Şekil 3) \%20 pomza ikameli çimento harçlarında olduğu belirlenmektedir. 90. hidratasyon gününde ise en fazla değişimin $0,15 \mathrm{MPa}$ farkla \%0,26 hata oranıyla \%10 diatomit ikameli çimento harçlarında olduğu belirlenmiştir (Şekil 4). Modelden elde edilen sonuçlar genel olarak değerlendirildiğinde 2 ve 7. hidratasyon günlerinde kabul edilebilir hata oranıyla basınç dayanımı değerlerine ulaşılırken 28 ve 90. hidratasyon günlerinde ise neredeyse gerçek değerlere yakın tahmin değerlerinin elde edilebildiği görülmektedir.

\section{SONUÇLAR VE ÖNERİLER}

Yapılan bu çalışmada elde edilen sonuçlara göre;

- Test aşamasındaki deneysel sonuçlar ile ANFIS modelinden elde edilen sonuçlarının karşılaştırılmasında $\mathrm{R}^{2}$, MAPE ve RMS gibi istatistiksel verilerin sirasiyla 0,9666, 6,660468 ve 2,557450 olduğu ve bu verilerin oldukça iyi olduğu,

- 2. hidratasyon günündeki basınç dayanımlarındaki en fazla değișimin \%16,18 hata oranıyla \%20 pomza ikameli çimento harçların basınç dayanımlarında olduğu,

- 7. hidratasyon gününde en fazla değişimin \%12,76 hata oranıyla \%20 pomza ikameli çimento harçların basınç dayanımlarında olduğu,

- 28. idratasyon gününde en fazla değişimin \%1,74 hata oranıyla \%20 pomza ikameli çimento harçların basınç dayanımlarında olduğu, 
- 90. hidratasyon gününde en fazla değişimin $\% 0,26$ hata oranıyla \%10 diatomit ikameli çimento harçlarında olduğu,

- Modelden elde edilen sonuçlar genel olarak değerlendirildiğinde 2 ve 7 . hidratasyon günlerinde kabul edilebilir hata oranıyla basınç dayanımı değerlerine ulaşılırken 28 ve 90 . hidratasyon günlerinde ise neredeyse gerçek değerlere yakın tahmin değerlerinin elde edilebildiği dolayısıyla giriş ve çıkış değişkenleri arasında bir uyumun olduğu,

- $\mathrm{Bu}$ veriler 1 şı̆̆ında geliştirilen bu modelin faydalı ve güçlü bir model olduğu, dolayısı ile bu ANFIS modeliyle oldukça iyi basınç dayanımı tahminlerinin elde edilebildiği düşünülmektedir.

Sonuç olarak geliştirilen bu ANFIS modeliyle pomza ve diatomit ikamesi ile hazırlanmış çimento harçlarının basınç dayanımlarının çok küçük hata ve kısa bir sürede tahmininin yapılabileceği ifade edilebilir. Ayrıca bu metodun yanında farklı yapay zeka tabanlı uygulamalar ve modellerle tahmin edilmesinin faydalı olabileceği düşünülmektedir.

\section{Çıkar çatışması}

Çalışma ile ilgili olarak, herhangi bir kişi veya kurumla çıkar çatışmasının bulunmadığını Yazarlar olarak onayliyoruz.

\section{Teşekkür}

Yazarlar, bu modelde kullanılmak üzere doktora çalışmasına ait olan deneysel verilerini paylaşan Yılmaz Koçak ve İbrahim Pınarcıya teşekkür ederler.

\section{KAYNAKÇA}

[1] Mohamed, M., \& Tran, D. Q. (2021). Risk-based inspection for concrete pavement construction using fuzzy sets and bayesian networks. Automation in Construction, 128, 103761.

[2] Güvenç, U., Koçak, B., \& Koçak, Y. (2021). Portland Kompoze Çimentosunun Priz Süresine Metakaolin Etkisinin Bulanık Mantıkla Tahmini. Eskişehir Türk Dünyası Uygulama ve Araştırma Merkezi Bilişim Dergisi, 2(2), 29-34.

[3] Gutierrez-Garcia, F. J., Alayon-Miranda, S., Gonzalez-Diaz, E., \& Perez-Diaz, P. (2017). Fuzzy model for calculating of cement mortar ratios. DYNA, 92(6), 688-695.

[4] Koçak, B., Koçak, Y., \& Yücedă̆, İ. (2020). Prediction of Flexural Strength of PortlandComposite Cement Mortars Substituting Metakaolin Using Fuzzy Logic. Düzce Üniversitesi Bilim ve Teknoloji Dergisi, 8(4), 2377-2387.

[5] Ozcan, G., Kocak, Y., \& Gulbandilar, E. (2018). Compressive strength estimation of concrete containing zeolite and diatomite: an expert system implementation. Computers and Concrete, 21(1), 21-30.

[6] Sevim, U. K., Bilgic, H. H., Cansiz, O. F., Ozturk, M., \& Atis, C. D. (2021). Compressive strength prediction models for cementitious composites with fly ash using machine learning techniques. Construction and Building Materials, 271, 121584.

[7] Ozcan, G., Kocak, Y., \& Gulbandilar, E. (2017). Estimation of compressive strength of BFS and WTRP blended cement mortars with machine learning models. Computers and Concrete, 19(3), 275-282.

[8] Shariati, M., Mafipour, M. S., Mehrabi, P., Bahadori, A., Zandi, Y., Salih, M. N., ... \& PoiNgian, S. (2019). Application of a hybrid artificial neural network-particle swarm optimization (ANNPSO) model in behavior prediction of channel shear connectors embedded in normal and high-strength concrete. Applied Sciences, 9(24), 5534.

[9] McElroy, P. D., Bibang, H., Emadi, H., Kocoglu, Y., Hussain, A., \& Watson, M. C. (2021). Artificial neural network (ANN) approach to predict unconfined compressive strength (UCS) of oil and gas well cement reinforced with nanoparticles. Journal of Natural Gas Science and Engineering, 88, 103816.

[10] Adesanya, E., Aladejare, A., Adediran, A., Lawal, A., \& Illikainen, M. (2021). Predicting shrinkage of alkali-activated blast furnace-fly ash mortars using artificial neural network (ANN). Cement and Concrete Composites, 124, 104265.

[11] Maqsoom, A., Aslam, B., Gul, M. E., Ullah, F., Kouzani, A. Z., Mahmud, M. A., \& Nawaz, A. (2021). Using Multivariate Regression and ANN Models to Predict Properties of Concrete Cured under Hot Weather. Sustainability, 13(18), 10164.

[12] Sakthivel, P. B., Ravichandran, A., \& Alagumurthi, N. (2016). Modelling and prediction of flexural strength of hybrid mesh and fiber reinforced cementbased composites using Artificial Neural Network (YSA). Int $\mathrm{J}$ GEOMATE Geotech Const Mat Env, 10, 1623-1635.

[13] Mansouri, I., \& Kisi, O. (2015). Prediction of debonding strength for masonry elements retrofitted with FRP composites using neuro fuzzy and neural network approaches. Composites Part B: Engineering, 70, 247-255.

[14] Koçak, Y., \& Gülbandılar, E. (2016). $\mathrm{MgSO}_{4}$ Etkisindeki Betonların Basınç Dayanımının ANFIS ile Tahmini. 8. International Aggregates Syposium, Dumlupınar Universitesi, Kütahya, Turkey, 251262.

[15] Armaghani, D. J., \& Asteris, P. G. (2021). A comparative study of YSA and ANFIS models for the prediction of cement-based mortar materials compressive strength. Neural Computing and Applications, 33(9), 4501-4532.

[16] Amin, M. N., Javed, M. F., Khan, K., Shalabi, F. I., \& Qadir, M. G. (2021). Modeling Compressive Strength of Eco-Friendly Volcanic Ash Mortar using Artificial Neural Networking. Symmetry, 13(11), 2009.

[17] TS EN 197-1. Çimento- Bölüm 1: Genel ÇimentolarBileşim, Özellikler ve Uygunluk Kriterleri. Türk Standartları, Ankara, 2012.

[18] TS EN-196-1. Çimento deney metodlar1-Bölüm 1: Dayanım tayini. Türk Standartları, Ankara, 2016. 
[19] Temel R. (2017). Uçak Kara Kutusundan Alınan Veriler Kullanılarak Hücum Açısı Ve Mach Sayısının YSA ve ANFIS ile Tahmini. Yüksek Lisans Tezi, Erciyes Üniversitesi Fen Bilimleri Enstitüsü, Kayseri.

[20] Aali, K. A., Parsinejad, M., \& Rahmani, B. (2009). Estimation of Saturation Percentage of Soil Using Multiple Regression, YSA, and ANFIS Techniques. Comput. Inf. Sci., 2(3), 127-136.

[21] Jang, J. S. (1996, September). Input selection for ANFIS learning. In Proceedings of IEEE 5th International Fuzzy Systems (Vol. 2, pp. 14931499). IEEE.

[22] Bhavani Chowdary, T., \& Ranga Rao, V. (2021). Design and Analysis of Lightweight AlkaliActivated Slag and Fly Ash Geopolymer Mortars using ANFIS-SSO. Iranian Journal of Science and Technology, Transactions of Civil Engineering, 114. 